\title{
Peer Influence in Internet and Digital Game Addicted Adolescents: Is Internet / Digital Game Addiction Contagious?
}

\author{
Selim Gunuc ${ }^{1, *}$ \\ ${ }^{1}$ Yuzuncu Yil University, Faculty of Education, Department of Computer Education and Instructional Technologies, Post Code: 65000, Van, Turkey \\ "Corresponding author: Selim Gunuc, Yuzuncu Yil University, Faculty of Education, Department of Computer Education and Instructional Technologies, Post Code: 65000, Van, \\ Turkey. Tel: +90-5057506254, E-mail: selimgunuc@hotmail.com
}

Received 2015 October 08; Revised 2016 May 14; Accepted 2016 June 09.

\begin{abstract}
Background: Internet and digital game addictions can be seen mostly amongst adolescents, although it is possible to see individuals at all ages suffering from these problems. According to international literature, the prevalence of Internet and digital game addictions amongst adolescents increased in several countries.

Objectives: This study tried to seek answers to the following research questions: does peer influence have a role in the development of Internet and digital game addictions, do peers form a group involving addicted members or non-addicted members and lastly, are Internet and digital game addictions "contagious or infectious" amongst best friends?

Patients and Methods: The study was carried out on 184 students from a high school located in the Eastern part of Turkey. A personal information form, digital game addiction questionnaire and Internet addiction scale were all used as data collection tools. Relationships amongst adolescents were determined by a social network analysis (SNA).

Results: It was found that Internet / digital game addicted individuals formed close friend groups and interacted with other Internet/digital game addicted individuals and that the non-addicted individuals formed groups with other non-addicts.

Conclusions: Consequently the SNA in this study revealed that peer influence is an important factor in explaining the causes of the spread of Internet and digital game addictions.
\end{abstract}

Keywords: Adolescent, Behavior, Addictive, Internet, Social Networks, Peer Influence

\section{Background}

In line with the spread of the Internet throughout the world and with the increasing number of its users, such problematic Internet use as online gaming disorder and Internet addiction are likely to increase. Internet addiction, though not currently found fully in the scope of "diagnostic and statistical manual of mental disorders, fifth edition" (DSM-5), is considered to be similar to "online gaming disorder" found in DSM-5. These symptoms include mood modification, salience, conflict, relapse, preoccupation with gaming/Internet, lying or hiding gaming/Internet use, loss of Interest in other activities, defensiveness and anger, social and psychological withdrawal, tolerance, using gaming/Internet as an escape, excessive use and negative consequences (1).

Internet and digital game addictions can be seen mostly amongst adolescents, although it is possible to see individuals at all ages suffering from these problems. According to the international literature, the spread of Internet addiction amongst adolescents in several countries is as follows: $10.1 \%$ in Turkey (2), 5.8\% in Poland (3), 5.8\% in Italy (4), $13.5 \%$ in China (5), $4.6 \%$ in Romania (6), $17.7 \%$ in Romania (7), $5.1 \%$ to $10.6 \%$ in Germany $(7,8), 4.4 \%$ to $13.9 \%$ in Europe $(6,7)$. It could be stated that these differences changing from one society to another result from a number of factors such as culture, access to technology, age, parental education, level of income, different measurement tools and different measurement techniques, time of research conducted and selection of research samples (6, 7).

If there is an increase in Internet and digital game addictions, as mentioned by the findings above, then how does this spread occur? Undoubtedly, this increase is caused by factors such as access to technology, low Internet cost, games available in mobile phones and easy access to the Internet via mobile phones. However, the basic factor is an issue of interest. During adolescence, the influence of parents and peers is important for the development of attitudes and behaviors (9). While examining the spread of Internet and digital game addictions especially amongst adolescents, peer groups and peer relationships should be taken into account.

There are several theories put forward to explain the influence of social relationships and peer relationships on their attitudes towards each other. Social learning theory (10), suggests that behaviors are developed through modeling from family members, peers, media and other social 
sources (11). Adolescents spend an increasing amount of their time with peers compared to parents. The higher level of exposure results in adolescents being more likely to imitate peers who have modeled positive rewards from internet and games. According to the Social Identity Theory (12), an individual generally chooses a group in line with his or her self-concept. Every group has a certain identity. If the individual is a person who uses the Internet and plays digital games, he/she wants to be a member of a group made up of members interested in the Internet and digital games. According to this theory, generally, the group is expected to be homogenous. In other words, addicted members are expected to form a group or establish close friendships with other addicted members and nonaddicted members with other non-addicts. The Primary Socialization Theory proposes that norms regarding behavior are transmitted through social sources. The primary social source are parents and peers. These social sources are combined with individual factors to increase the likelihood of participating in a behavior (11). Social Network Theory focuses on relationships and interdependence between individuals within a social system such as school and relationships. According to the theory, individuals living in a social system interact with one another and influence each other in terms of their behavior, attitudes and the decisions they are making (11).

Peers are a major source of influence on adolescents, for instance, in terms of substance/drug use $(11,13)$. It is believed that best friends also influence each other's attitudes and behaviors (14). Adolescents are significantly similar to friends when it comes to behaviors, characteristics, attitudes and personality $(15,16)$. The group accepts an adolescent if the group members share common characteristics with that adolescent or the adolescent admitted to the group takes the behaviors and attitudes of that group. Group members are likely to demonstrate bad behavior more easily, especially by taking courage from one another. In addition, group members, especially the group leader, tend to take the behaviors and attitudes of dominant group members (14).

In related literature, there are several other studies examining peer influence on substance use and drug use. Peer influence appeared as one of the important factors in understanding adolescents' behaviors $(15,17,18)$. In addition, the role of peer influence in such behaviors such as Internet use and digital game playing, which both allow sharing amongst adolescents, is an issue to be investigated. Furthermore, it is important to reveal whether peer influence is a factor when explaining how Internet and digital game playing becomes widespread amongst adolescents. Although several studies have examined the relationships between peer influence and Internet use or Inter- net addiction (19-21), the number of such studies is quite limited. In addition, the present study did not only focus on peer influence but also tried to explain the spread of Internet and digital game addictions with the help of the Social Network Analysis (SNA).

\section{Objectives}

This study aimed to seek answers to the following research questions: does peer influence have a role in the development of Internet and digital game addictions, do peers form a group involving addicted members or nonaddicted members, in other words, is it true that adolescents who are addicted to the Internet and digital games are best friends with other adolescents who are addicted to the Internet and digital games, and those who are not addicted to the Internet and digital games are best friends with other non-addicted members and lastly, are Internet and digital game addictions "contagious or infectious" amongst best friends?

\section{Patients and Methods}

\subsection{Research Model}

The study was a correlational research, which is why a social network analysis (SNA) was used. SNA is the mapping and measuring of relationships between people or groups. Also, the correlational research is done to determine relationships amongst two or more variables and to explore their implications for cause and effect (22).

\subsection{Participants}

The study was carried out on 184 students from a high school (grades 9 and 11) located in the Eastern part of Turkey. While determining the research sample, the purposive sample method was used. Peer relationships can be determined more clearly within a social system. School environment is an important social system for adolescents; therefore, the present study was carried out in a school setting.

The ages of the adolescents participating in the study ranged between 15 and 18 . The measurement tools were given to the adolescents who were determined randomly and 55 of all the participating adolescents said they used the Internet but never played computer/video games. Therefore, the analysis for game addiction was conducted with the remaining 129 adolescents, while used 184 adolescents for Internet addiction analysis. 


\subsection{Instrumentation}

\subsubsection{Personal Information Form}

The research data regarding the adolescents' names and surnames, their gender, age, class grade and the names and surnames of their best friends were collected with a personal information form. The concept of "best friends" was preferred to "close friends" because best friends are thought to have the greatest peer influence on adolescents (14). On the other hand, in the Turkish language, best friends and close friends are two concepts with quite similar meanings.

\subsubsection{Digital Game Addiction Questionnaire (DGAQ)}

The digital game addiction questionnaire was developed by the researcher. In the process of developing the items, nine indicators in relation to the Internet Gaming Disorder found in DSM-5 were taken as a reference. In this study, no discrimination was made between computer games, online games and video games and the items regarding the games played in the digital environment were developed specifically for the questionnaire. One item was prepared for each indicator. Five field experts were asked for their views on a total of nine items and content validity as well as face validity were achieved. For the scoring of the DGAQ, a five-point Likert-type scale was used with scores and answers ranging from '(1) Strongly Disagree' to '(5) Strongly Agree'. Certain evidence was necessary to use for the DGAQ as a continuous variable and as a reliable tool. For this purpose, item analyses were conducted. The correlation values between each item, the DGAQ total score and also between each item pair were found significant at $\mathrm{P}<$ 0.05 . The reliability of the DGAQ was calculated as 0.71 . The data set regarding the DGAQ demonstrated a normal distribution. The findings obtained regarding the item analyses revealed that the DGAQ could be used for the intended measurement.

\subsubsection{Internet Addiction Scale (IAS)}

IAS was developed in Turkish by Gunuc and Kayri (2) via a study carried out with 754 adolescents. The average participant age was 15.8. The scale is made up of 35 items. The scale is consisted of four sub-factors which were defined as "Withdrawal", "Controlling difficulty", "Disorder in Functionality" and "Social Isolation". The five-point Likert-type scale was rated as (1) strongly disagree and (5) Strongly Agree and has a Cronbach's Alpha internal consistency coefficient of 0.94. The reliability of IAS was calculated as 0.92 in the present research. Higher scores received from the scale indicate Internet addiction.

\subsection{Procedure and Data Analysis}

A SNA examines the structure of social relationships amongst actors (i.e. adolescents). Network data is defined by actors and by relations/interactions (or nodes and ties, etc.). In the present study, actors are adolescents. A direct connection is the connection between two people. A person can also be indirectly connected to another person through knowing a "friend of a friend" $(23,24)$.

The data regarding the relationships between the students were created as a data matrix with the UCINET computer software and then analyzed. In order to discriminate between the adolescents' addiction scores, their addiction scores were examined with a two-step cluster analysis and classified as non-addicted, moderately addicted and addicted. In order for the relationships between peer groups to be obvious and easy to interpret, three different colors were used for the non-addicted, moderately addicted and addicted groups. Due to this, the relationship between the addictions and best friends was interpreted. This analysis process was conducted for both Internet addiction and digital game addiction to interpret how addiction spreads amongst adolescents.

\section{Results}

When the relationships between the students were examined, it was seen that close friendships were established with the students in other classes rather than with those in the same class. Figure 1 presents the close friendship relationships with respect to the variables of gender and class grades.

Of all the 184 adolescents (or nodes) participating in the study, three of them reported that they did not have any close friends and 32 stated that they had close friends from other classes or from outside of school. For this reason, these adolescents were not included in the graph obtained via the analysis. Thus, the relationships (or ties) regarding a total of 149 adolescents can be seen in Figure 1.

In order to examine the close friendships amongst the adolescents with respect to Internet and digital game addictions, their Internet addiction scores and digital game addiction scores were transformed into categorical data. This way, the adolescents divided into groups depending on their addiction scores were colored in the graph to interpret the results more easily. While categorizing the data, a two-step cluster analysis was conducted according to the total scores regarding Internet and digital game addictions. Table 1 presents the findings obtained.

As seen in Table 1, the adolescents' Internet and digital game addictions were grouped as non-addicted, moderately addicted and addicted. Accordingly, 9.2\% of all the 


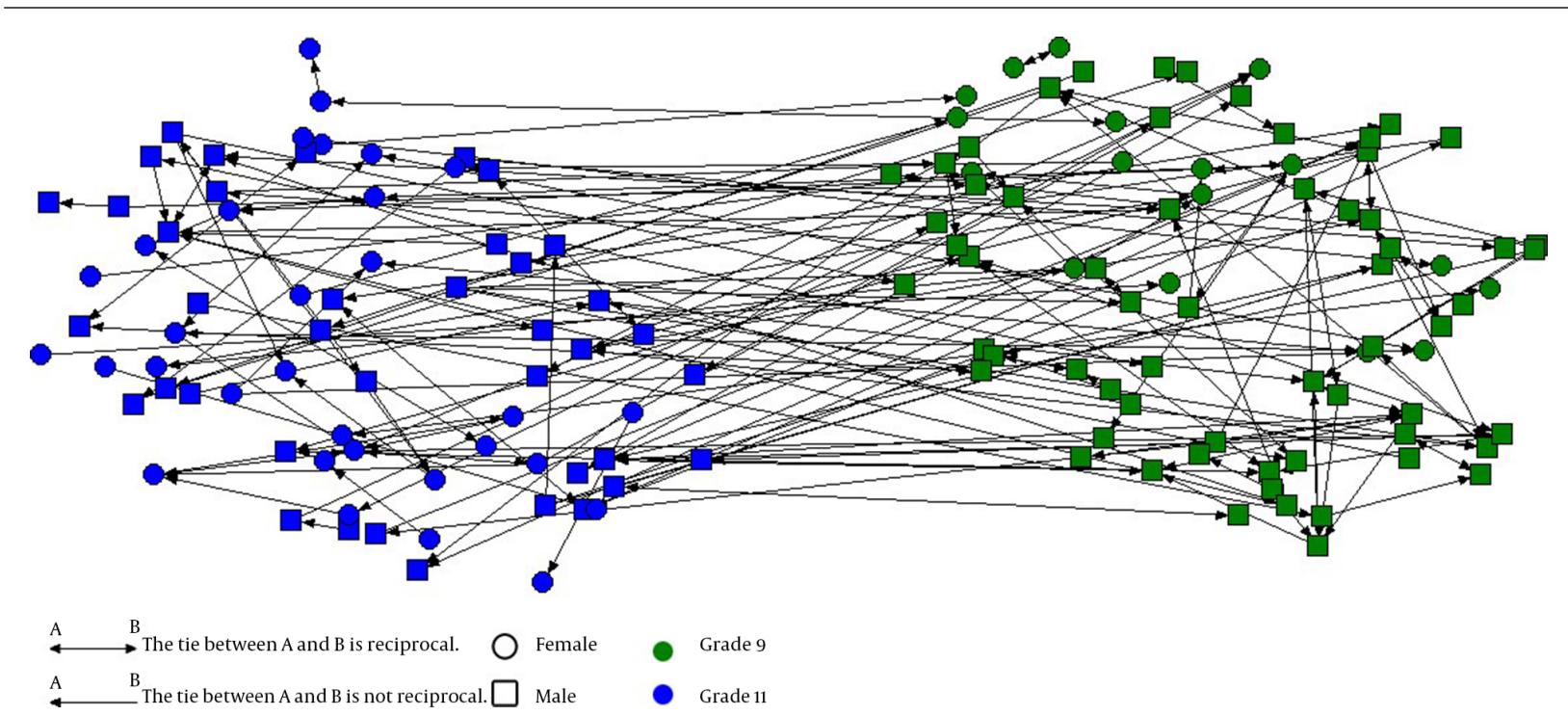

Figure 1. SNA Graph Demonstrating the Close Friendships with Respect to the Variables of Gender and Class Grade

Table 1. Two-Step Cluster Analysis Findings Regarding the IAS and DGAQ Data

\begin{tabular}{llccc}
\hline IAS & & N & \% of Total & Mean \pm SD \\
\hline & Non-addicted & 88 & 47.8 & $50.7 \pm 8.2$ \\
\hline Moderately addicted & 79 & 42.9 & $77.7 \pm 7.8$ \\
\hline Addicted & 17 & 9.2 & $112.8 \pm 10.3$ \\
\hline Total & 184 & 100.0 & $68.0 \pm 20.9$ \\
\hline \multirow{2}{*}{ DGAQ } & & & \\
\hline & Non-addicted & 45 & 35.2 & $14.7 \pm 2.4$ \\
\hline & Moderately addicted & 63 & 49.2 & $22.5 \pm 2.5$ \\
\hline & Addicted & 20 & 15.6 & $32.1 \pm 2.8$ \\
\hline & Total & 128 & 100.0 & $21.3 \pm 6.4$ \\
\hline
\end{tabular}

adolescents could be said to be Internet-addicted and 15.6\% of them could be said to be digital game-addicted. However, it was also seen that the percentage of the moderately addicted group, which was at addiction risk, was quite high. Figures 2 and 3 demonstrate the social network analysis conducted regarding Internet and digital game addictions.

When Figure 2 is examined, it is seen that the "best friends' relationships between the students were categorized from "isolated students (those with no friend)" to "the group of 22 students". When the groups of two or three members and the groups of multiple members were examined, it was seen in general (not for all groups) that Internet-addicted individuals formed best friend groups with other Internet-addicted individuals and that non- addicted individuals formed best friend groups with other non-addicted individuals. This is more obvious in the groups of non-addicted and moderately addicted individuals (especially due to their higher percentages). In addition, it was seen that addicted individuals established best friend relationships generally with addicted or moderately addicted individuals. Lastly, two of the three individuals found on the top left corner of the graphs who did not have any close friends were moderately addicted.

Similarly, according to Figure 3, fewer relationships are seen in the SNA graph as the gamers were fewer in number than the Internet users. In addition, when the groups of two or three members, multiple members and especially the one-on-one relationships are examined, it is seen that the game-addicted individuals established close friendships with game-addicted individuals and that nonaddicted individuals established such relationships with other non-addicted ones. However, while examining the within-group relationships, the direct and indirect relationships within the group should be taken into consideration. In respect to this, it should be remembered that some individuals are not central members in the group and that they just have indirect relationships with several group members. As for the 17 students found on the left of the graph, the friends of these 17 students were not included in the data analysis to interpret the results of the analysis more clearly due to the fact that their close friends never played digital games. On the other hand, the fact that most of these 17 students were addicted to games was an interesting find. Lastly, when the first three individuals on 


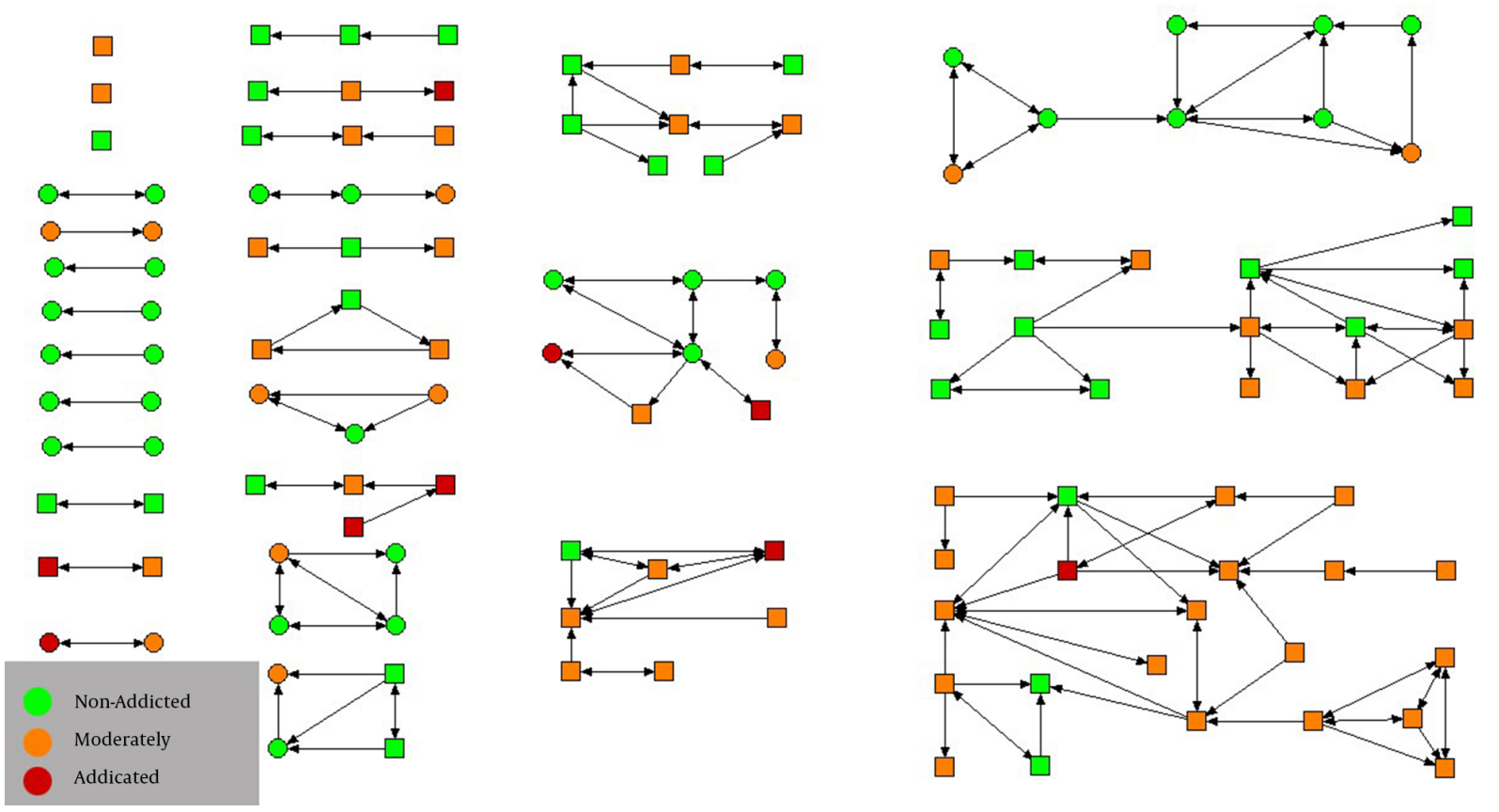

Figure 2. SNA Regarding Peer Influence on Internet Addiction
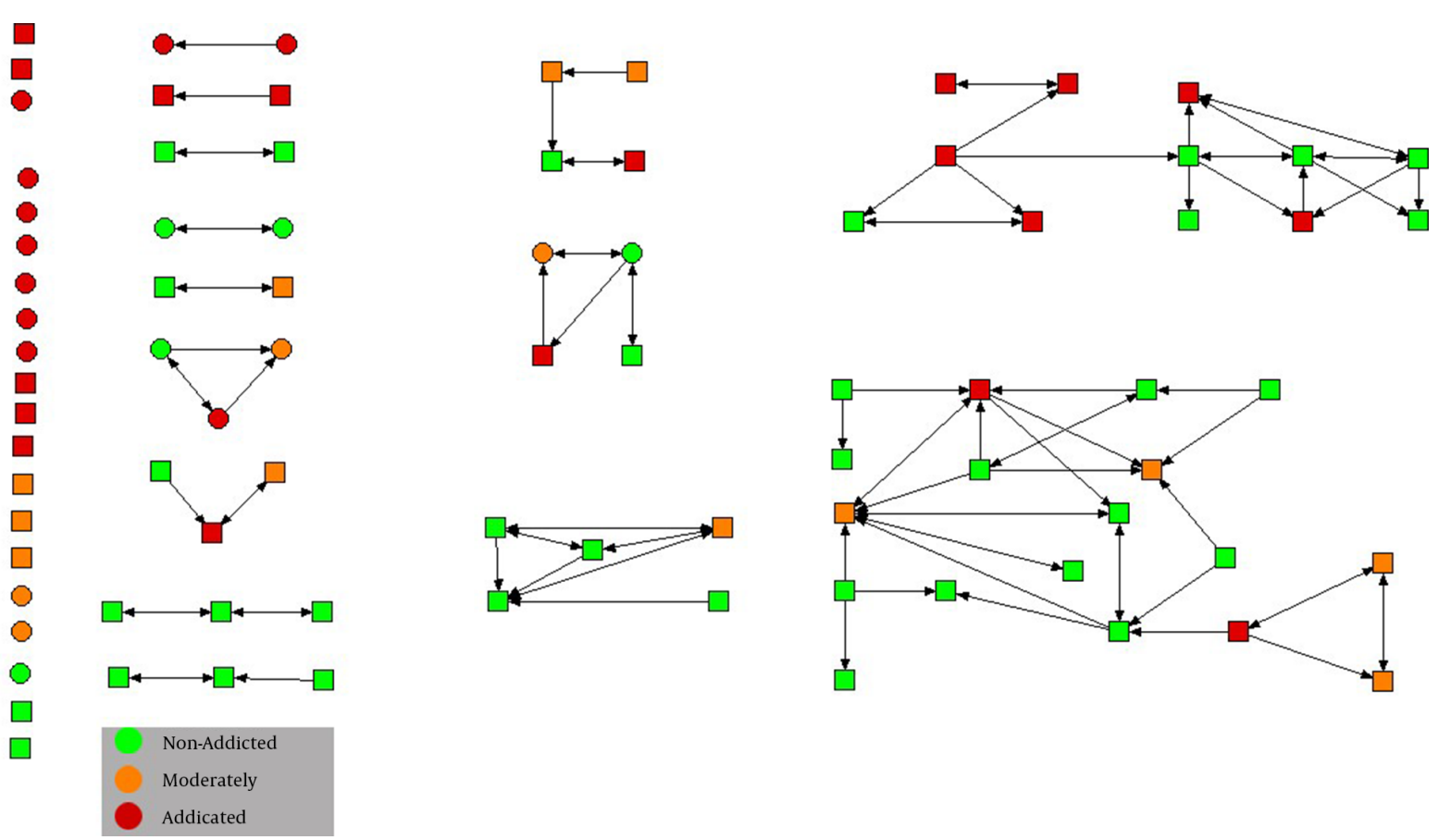

Figure 3. SNA Regarding Peer Influence on Digital Game Addiction

the left side of the graph (isolates) were examined, it was

seen that these individuals did not have any close friends 
and that all were obviously game-addicts.

\section{Discussion}

Related theories in literature support the findings obtained in the present study. However, it should be remembered that the theories be focused on peer groups rather than on best friends or close friends. Regarding adolescents, group dynamics are important for peer groups, especially for the groups involving close friendships. In respect to this group dynamics can be explained with the Social Identity Theory as well as other theories. According to this theory, cohesion amongst group members, their interactions, sharings and other areas of common interest are important. The group has an identity. If this identity involves interest in the Internet and digital games, adolescents without this interest are not included in the group nor accepted to the group. For this reason, adolescents aware of the group identity want to adapt to this identity and open themselves to this behavior. On the other hand, according to this theory, individuals, before joining the group, compare their own identities with the group identity. If their own identities resemble the group identity, they want to join the group. In addition, according to the theory, groups are generally homogenous; in other words, groups are expected to be divided as addicted and non-addicted. However, in this study, this perspective of the theory was not tested because it was not examined whether the individuals got addicted after they established close friendships (peer influence) or after they started using the Internet/games to become a member of the group (to make friends/to join a group). In addition, the Social Network Theory focuses on the interaction between group members. Group members are influenced by the attitudes and behaviors of especially central members. Technology is one of the important sources of sharing and common interest among adolescents. Therefore, regarding the Internet and digital games, which are both quite attractive and entertaining, adolescents could dominate other group members and transfer this behavior to them. According to the Social Learning Theory, the behaviors of their parents and peers observed by adolescents have an influence on these adolescents. They could imitate the problematic Internet use and digital game addiction behaviors of their peers. As they receive positive rewards from this behavior, they maintain the behavior. In this case, behaviors such as using the Internet and playing digital games that provide adolescents with entertainment and pleasure are inevitably transformed into addiction with time. According to this theory, addiction may not always occur because, as in the Social Identity Theory, individuals observe the behaviors of a group and process that behavior scientifically. In other words, they examine the group. Therefore, such factors as individuals' tendency towards addiction, their knowledge of healthy Internet use, their related experience and parental education are influential on their addiction. According to these theories, if there is an Internetaddicted or game-addicted group member amongst an adolescent's close friends, this reinforces that the adolescent has a likelihood of becoming Internet-addicted or game-addicted. If the adolescent joins a group of addicted members and makes close friends there, then he or she is more likely to get addicted; likewise, if the adolescent is in a group of non-addicted members, then he or she is less likely to get addicted (11). The results obtained in this study are generally supported by these theories as well.

Besides all, theories related to peer relationships could be said to focus on groups coming together for certain common sharings within a social system rather than on close friend relationships. On the other hand, these theories clarify the effects of best friends on each other's behavior. In addition, there might be differences between the dynamics of peer groups and best friends groups. For example, best friend groups, especially groups of two or three members, could be more influential on each other's behavior. A non-addicted group member can put forward 'warning' suggestions regarding especially addiction behavior and develop attitudes accordingly because an addicted member tends to follow his or her best friend's attitudes and suggestions. Obviously, the opposite could be true as well. However, there is generally a central individual, or more than one, in other peer groups with multiple members. In general, these individuals dominate the identity of the group, and it is quite difficult for a member to change the group structure.

In literature, some factors such as alcohol/drug use leads peers to establish new friendships $(11,13)$. However, compared to other factors such as sports, politics, alcohol/drug use and the roles of Internet and digital games are more effective on peers in the digital age. This is because children today are digital natives and are mostly interested in technology (25). Thus, it can be said that technology is an important determinant factor amongst peers. There is a significant role of Internet and game addictions for making close friends. As seen in the findings of this study, Internet and game addictions can also lead to isolation. In other words, Internet and game addictions result in losing friends. However, it is not possible to explain or understand the entire process with just a single factor.

Another finding obtained in the present study was the fact that adolescents without any close friends are Internet and game addicts. This finding is consistent with the findings of other studies in related literature. Lacking a 
close friend is one of the factors predicting Internet addiction for an adolescent (26). In addition, peer groups with two, three and multiple members formed depending on whether they are addicted or not gives clues to the way and cause of the spread of Internet and game addictions. Furthermore, the findings obtained in the present study allowed directing two questions to understand the main cause of the spread of addiction:1) Do adolescents have excessive tendency towards the Internet and digital games just to be accepted to the peer groups? 2) Or do they get addicted with time due to the influence of the attitudes and behaviors of their best friend(s) (peer influence)? In order to seek answers to these questions, interviews could be held with students using the "case study" method, this way, detailed data could be gathered regarding their addiction levels before and after their friendships with their close friends. In addition, adolescents' attitudes, behaviors, sharings and dialogues with their close friends should be observed. Taking all this data and SNA findings into account this will provide more information about how and why Internet and digital game addictions spread amongst adolescents. Learning and understanding this process is fairly important for the prevention and treatment of Internet and digital game addictions. Seeing that peer influence is very important, treating a single individual addicted to the Internet and digital games and avoiding the necessary precautions to be taken regarding his or her social environment could cause addiction to reappear with time. In this respect, it is important to view addiction from a broader perspective.

Peer influence is just one of the factors important for understanding addicted adolescents. The fact that addiction levels of some individuals in a group are not similar to the addiction level of the entire group can be explained with the influence of other factors. One of these factors is the duration of interactions. Undoubtedly, the present study reflected a very small section of the participating individuals' lives. In Turkey, there are certain difficulties conducting periodical measurements on the same students at a school. However, in future studies, the changes based on peer interactions could be observed by focusing on a section of students' lives. The second factor is family. According to the Primary Socialization Theory and Social Learning Theory, besides peer relationships and school, family relationships are also important sources for adolescents' development of attitudes and behaviors (9). Individuals may withdraw themselves from their families and prefer their peers as role models due to such factors as their relationships with their families and the perceived social support from their families. Although this does not always lead to bad results, individuals may not eventually feel themselves responsible for their families and thus develop bad habits.
In addition, whether parents are Internet/game addicted or not and whether they are knowledgeable about the safe use of Internet could have an influence on adolescents. Although families and peer groups are influential on Internet and digital game addictions, the present study examined the influence of only the peer groups regarding Internet and digital game addictions because peer influence is believed to be more dominant on adolescents when compared to their families (27). On the other hand, parents are also believed to be influential on individuals' development of attitudes and behaviors. For this reason, future studies could examine whether parents or peer groups are more influential on the development and prevention of Internet and digital game addictions. The third factor is related to the individual differences of adolescents. According to Primary Socialization Theory, it is necessary to take individual factors and individual differences into consideration. Adolescents cannot be expected to be influenced to the same extent by peer interaction. Some adolescents are more open to changes, and they can adapt themselves to any positive/negative situation more easily.

\subsection{Conclusions}

The present study tried to understand not only how Internet and digital game addictions spread but also whether there is related peer influence or not. When other similar studies in literature are examined (2), it is seen that there is a striking increase in Internet and digital game addictions amongst adolescents. Considering especially the total percentages of addicted and moderately addicted individuals in the present study, it is seen that the percentage of addiction amongst adolescents is quite high. In addition, the SNA in this study revealed that peer influence is an important factor in explaining the causes of the spread of Internet and digital game addictions. In literature, there is a limited amount of related research, which supports the findings obtained in the present study (19). The SNA was conducted focusing on best friends/close friends. Therefore, not all adolescents in crowded groups can be said to be close friends with each other. There were central members in some groups, while some members were observed to be marginal. However, considering the fact that they were at the same school or in the same class, the group members could be said to know each other even if indirectly. Therefore, while evaluating the social network graphs, the focus was on the group members who were in direct interaction with each other rather than on the whole group. In respect to this finding, it is possible that Internet/game addicted individuals formed close friends groups with and interacted with other Internet/game addicted individuals and that the non-addicted individuals 
with other non-addicts. In addition, peer influence was more obviously observed on digital game addiction.

Evaluation of social network analysis by gathering data regarding adolescents' related knowledge, awareness and interest could help obtain new findings in future studies. In addition, the present study could be regarded as a pilot study in relation to the research subject because no data was collected from the families of the adolescents and from their schools due to several obstacles and because no interview was held with the adolescents. This was accepted as the limitation to the study. For this reason, future studies could gather detailed data from families and peers directing the same research questions mentioned above.

\section{References}

1. American Psychiatric Association (APA). . Diagnostic and statistical manual of mental disorders (DSM). 5 ed. Arlington: VA American Psychiatric Publishing; 2013.

2. Gunuc S, Kayri M. The profile of internet dependency in turkey and development of internet addiction scale: Study of validity \& reliability. Hacettepe Univ J Edu. 2010;39.

3. Zboralski K, Orzechowska A, Talarowska M, Darmosz A, Janiak A, Janiak $M$, et al. The prevalence of computer and Internet addiction among pupils. Postepy Hig Med Dosw (Online). 2009;63:8-12. [PubMed: 19252459].

4. Poli R, Agrimi E. Internet addiction disorder: prevalence in an Italian student population. Nord J Psychiatry. 2012;66(1):55-9. doi: 10.3109/08039488.2011.605169. [PubMed: 21859396].

5. Wu X, Chen X, Han J, Meng H, Luo J, Nydegger L, et al. Prevalence and factors of addictive Internet use among adolescents in Wuhan, China: interactions of parental relationship with age and hyperactivity-impulsivity. PLoS One. 2013;8(4):ee61782. doi: 10.1371/journal.pone.0061782. [PubMed: 23596525].

6. Durkee T, Kaess M, Carli V, Parzer P, Wasserman C, Floderus B, et al. Prevalence of pathological internet use among adolescents in Europe: demographic and social factors. Addiction. 2012;107(12):2210-22. doi: 10.1111/j.1360-0443.2012.03946.x. [PubMed: 22621402].

7. Tsitsika A, Janikian M, Schoenmakers TM, Tzavela EC, Olafsson K, Wojcik S, et al. Internet addictive behavior in adolescence: a crosssectional study in seven European countries. Cyberpsychol Behav Soc Netw. 2014;17(8):528-35. doi: 10.1089/cyber.2013.0382. [PubMed: 24853789].

8. Wolfling K, Muller KW. [Pathological gambling and computergameaddiction. Current state of research regarding two subtypes of behavioural addiction]. Bundesgesundheitsblatt Gesundheitsforschung Gesundheitsschutz. 2010;53(4):306-12. doi: 10.1007/s00103-010-1038-7. [PubMed: 20195558].

9. Armsden GC, Greenberg MT. The inventory of parent and peer attachment: Individual differences and their relationship to psychologi- cal well-being in adolescence. J Youth Adolesc. 1987;16(5):427-54. doi: 10.1007/BF02202939. [PubMed: 24277469].

10. Bandura A. Social learning theory. Englewood Cliffs, NJ: Prentice Hall; 1977.

11. Kobus K. Peers and adolescent smoking. Addiction. 2003;98 Suppl 1:37-55. [PubMed: 12752361].

12. Abrams D, Hogg MA. Social identifications: A social psychology of intergroup relations and group processes. Routledge; 2006.

13. Bahr SJ, Hoffmann JP, Yang X. Parental and peer influences on the risk of adolescent drug use. J Prim Prev. 2005;26(6):529-51. doi: 10.1007/s10935-005-0014-8. [PubMed:16228115].

14. Simons-Morton BG, Farhat T. Recent findings on peer group influences on adolescent smoking. J Prim Prev. 2010;31(4):191-208. doi 10.1007/s10935-010-0220-x. [PubMed: 20614184].

15. Bauman KE, Fisher LA. On the measurement of friend behavior in research on friend influence and selection: Findings from longitudinal studies of adolescent smoking and drinking. J Youth Adolesc 1986;15(4):345-53. doi: 10.1007/BF02145731. [PubMed: 24301833].

16. Urberg KA, Tolson JM, Degirmencioglu SM. Friendship selection in adolescent friendship networks. J Soc Pers Relatsh. 1998;15:703-10.

17. Huba GJ, Bentler PM. The role of peer and adult models for drug taking at different stages in adolescence. J Youth Adolesc. 1980;9(5):44965. doi: 10.1007/BF02087681. [PubMed: 24318204]

18. Urberg KA, Luo Q, Pilgrim C, Degirmencioglu SM. A two-stage model of peer influence in adolescent substance use: individual and relationship-specific differences in susceptibility to influence. Addict Behav. 2003;28(7):1243-56. [PubMed: 12915166].

19. Deng YX, Hu M, Hu GQ, Wang LS, Sun ZQ. [An investigation on the prevalence of internet addiction disorder in middle school students of Hunan province]. Zhonghua Liu Xing Bing Xue Za Zhi. 2007;28(5):445-8. [PubMed: 17877171].

20. Lam CB, Chan DK. The use of cyberpornography by young men in Hong Kong: some psychosocial correlates. Arch Sex Behav. 2007;36(4):588-98. doi: 10.1007/s10508-006-9124-5. [PubMed: 17186123].

21. Soh PCH, Charlton JP, Chew KW. The influence of parental and peer attachment on Internet usage motives and addiction.. First Monday. 2014;19(7).

22. Fraenkel JR, Wallen NE, Hyun HH. How to design and evaluate research in education. 8 ed. New York: McGraw-Hill; 2012.

23. Ehrlich K, Carboni I. Inside Social Network Analysis. IBM Technical Report 2005. Available from: http://ppr.cs.dal.ca/sraza/files/social\% 20networks\%281\%29.pdf.

24. Hanneman RA. Introduction to social network methods. Riverside: University of California; 2001.

25. Prensky M. Digital natives, digital immigrants. On the Horizon. ;9(5):15.

26. Liu CY, Kuo FY. A study of Internet addiction through the lens of the interpersonal theory. Cyberpsychol Behav. 2007;10(6):799-804. doi: 10.1089/cpb.2007.9951. [PubMed: 18085967].

27. Aseltine RJ. A reconsideration of parental and peer influences on adolescent deviance. J Health Soc Behav. 1995;36(2):103-21. [PubMed: 9113137]. 